\title{
V8-Asp/Glu Protein Cleavage Reagent
}

National Cancer Institute

\section{Source}

National Cancer Institute. V8-Asp/Glu Protein Cleavage Reagent. NCI Thesaurus. Code C161895.

A protein cleavage reagent comprised of the bacterial serine proteinase V8-Asp/Glu that cleaves proteins into peptides at the C-terminal side of an asparagine, aspartate, glutamate or glutamine residue unless that residue is followed by a proline. 